ORIGINAL RESEARCH ARTICLE

\title{
Lecture capture and peer working: exploring study practices through staff-student partnerships
}

\author{
Geraint Evans ${ }^{\mathrm{a}^{*}}$ and Karl Luke \\ ${ }^{a}$ School of Social Sciences, Cardiff University, Cardiff, UK; ${ }^{b}$ School of Medicine, \\ Cardiff University, Cardiff, $U K$ \\ (Received: 26 July 2019; Revised: 8 January 2020; Accepted: 14 January 2020; \\ Published: 19 February 2020)
}

\begin{abstract}
As lecture capture technology and practice become ever more widespread in UK universities there is a growing body of literature that assesses the impact of these changes. However, there is still much to be understood about lecture capture and the full impact on student learning, especially in different institutional and subject contexts. This article describes two projects from a UK Russell Group University that worked in partnership with students to gain insights into the student experience regarding lecture capture. The article highlights insights gained in terms of how and why students use lecture recordings. This article focuses on one area in particular which has been less reported and warrants further investigation - students' use of lecture recordings in collaborative settings. The article considers some practical implications of such insights and argues that a nuanced understanding regarding the way students use lecture recordings for learning is required. The article also highlights how educationists can harness student partnerships to further our understanding of the complex interplays between technology and student learning.
\end{abstract}

Keywords: lecture recording; study practices; collaborative learning; student partnership; video lectures

\section{Introduction}

The provision of educational recordings, particularly the recordings of teaching events such as lectures (commonly known as lecture capture), is fast becoming an established practice within UK higher education. The Universities and Colleges Information Systems Association (UCISA) 2018 survey on Technology Enhanced Learning (TEL) (Walker et al. 2018) reports that $75 \%$ of responding higher education institutions (HEIs) utilise lecture capture technologies. Such solutions typically produce digital video and/or audio recording of lectures, usually synchronised with displayed lecture materials and published online via an institutional virtual learning environment (VLE). Often motivated by student demand, universities have adopted a variety of approaches in implementing and supporting lecture capture, but almost invariably cite similar aims; to enhance teaching and learning and to improve the wider student experience (Nordmann and McGeorge 2018). This article uses the term 'lecture capture' to indicate the process and practice of recording and releasing lectures to students, while a 'lecture recording' is a specific product or artefact - a recording of a lecture that a student can watch and listen to.

Even though lecture capture is continuously gaining popularity, it remains a controversial technology for many HEI staff who frequently express both pedagogic and

*Corresponding author. Email: evansg41@cardiff.ac.uk 
ethical concerns (Morris, Swinnerton, and Coop 2019; Newland 2017). This is possibly reflected in the discrepancies in implementation, provision, policy, and availability across the higher education sector (Rios-Amaya, Secker, and Morrison 2016). It is reported that lecture capture is used much more widely in the UK within the Russell Group of universities, which comprises 24 research-intensive universities, compared to other HEIs (Walker et al. 2018). There is continuing debate over the realised or abstract benefits, challenges, and side effects of lecture capture in areas including student experience, inclusion, and learning strategies, where there are concerns regarding a perceived increased emphasis on acquisition and rote-learning (Karnad 2013; Morris, Swinnerton, and Coop 2019; Witthaus and Robinson 2015).

Moreover, a large number of lecture capture studies focus on quantitative measures of change, such as student attainment or physical classroom attendance (Edwards and Clinton 2019; Nordmann et al. 2017). Insights are often further limited to the individual practices of students, which does not consider the impact of lecture capture on the learning community and on how students interact. Such positivist research can be viewed as oversimplifying the complex workings of lecture capture and the effects on learners (Luke 2020). As an initiative purportedly driven by student demand and expectation, there is surprisingly little evidence in the published lecture capture literature regarding the active role students can play in shaping their educational experiences (Morris, Swinnerton, and Coop 2019).

In recent years, student engagement has become a core aim of the higher education sector and, increasingly, is being linked to ideas about students' roles as partners in learning and teaching (Healey, Flint, and Harrington 2014). The concept of 'student partnership' has increasingly been used to describe ways in which institutions approach the important, yet difficult, task of engaging students with decisions around the design and delivery of their educational experience. This article considers two separate but related projects at Cardiff University (carried out in consecutive years in separate parts of the institution) that used staff-student partnership to explore the student experience of lecture capture.

\section{Background: Lecture capture at Cardiff University}

Cardiff University, a member of the Russell Group, implemented lecture capture in a phased rollout. A centralised system was first introduced during the 2015/16 academic year, initially in a small number of teaching spaces (approx. 30), but expansion of provision grew rapidly and by the 2017/18 academic year all core teaching spaces $(300+)$ were equipped with desktop, slide, and audio-capture capabilities, which included video-capture capability in a limited number of spaces.

Initially, lecture capture operated on an opt-in basis, before a University policy at the start of the 2018/19 academic year mandated that all timetabled lecture activities would be automatically recorded unless the presenter had 'opted out' in advance. The move towards an opt-out model was in direct response to student demand and was part of the University's strategic commitment to support flexible, digital, and independent learning (Cardiff University 2018). Both projects described in this article were undertaken before an opt-out model was implemented.

\section{Literature review}

\section{Lecture capture}

Whilst there is a growing body of literature on lecture capture the range of contexts, methodologies, and foci of enquiry make it difficult to summarise. Recent reviews 
on lecture capture highlight that it is a contentious educational technology, and the impact on teaching and learning is complex and contested (Morris, Swinnerton, and Coop 2019; Nordmann and McGeorge 2018). Several studies have attempted to unpack the potential pedagogic impact (both positive and negative) of lecture capture materials on student learning (Karnad 2013; O’Callaghan et al. 2017; Witthaus and Robinson 2015). Much of the literature has attempted to address important questions, such as the extent to which lecture capture supports student learning and improves subsequent attainment, although many disparities exist (Edwards and Clinton 2019; Nordmann et al. 2017; O'Callaghan et al. 2017).

Despite the ambiguity around impact and attainment, students highly value lecture capture (Witthaus and Robinson 2015). It has been suggested that students regard lecture recordings as important to their course satisfaction (Traphagan, Kucsera, and Kishi 2010). Several reasons for this have been offered, including lecture capture as mitigating the effects of illness and absence, and generally providing a 'safety net' to help learners through difficult periods in their studies (Nordmann et al. 2017). Students also value the flexibility of lecture recordings and the technical affordances available to re-watch or skip material depending on their needs (O'Callaghan et al. 2017). For similar reasons, students with learning disabilities and international students also report benefitting from the provision of lecture recordings, particularly the ability to revisit content at their own pace (Leadbeater et al. 2013).

Lecture capture is increasingly viewed as an assistive technology, offering opportunities for greater accessibility and inclusivity, and helping provide lecture materials in a variety of formats (Williams et al. 2017). Lecture capture is increasingly included in many institutional policies related to inclusive curriculum design (Nordmann et al. 2017). However, there is differing evidence regarding the actual level of student engagement with recordings and uncertainly concerning how learners position them as a learning resource (McKenna and Kopittke 2018).

The positive reception from students for lecture capture, the relatively efficient and cost-effective way in which recordings can be produced and made available (Meehan and McCallig 2019), and the benefits for inclusivity, have led some researchers to conclude that 'the positives of lecture recordings outweigh the negatives and its continued use in higher education is recommended' (O'Callaghan et al. 2017, p. 1). Some recent commentators suggest educators recognise that educational technologies are becoming an ever increasing feature of higher education and that the challenge now is to design inclusive curricula and pedagogical approaches, which include utilising technologies such as lecture capture, and to use these appropriately and effectively to support students' needs (Morris, Swinnerton, and Coop 2019). However, even accepting this position, there remain unresolved questions, including how best to practically and effectively support and implement lecture capture at a curriculum level within universities.

Much lecture capture literature can be criticised for oversimplifying the nuances and complexities surrounding learning and teaching within higher education (Luke 2020). Lecture capture practices offer a lens to re-explore the nature of teaching and learning within higher education, particularly the use of didactic delivery during lectures, and the educational relationships between the lecturer and their students (Morris, Swinnerton, and Coop 2019). Extending this, there is surprisingly little account in the existing literature of the active role that learners can take in informing strategic direction, contributing to the evidence base, and instigating positive change in this area. 


\section{Student partnership}

Student partnership is an idea that has gained much traction in higher education in recent years. What is different and unique about 'partnership' in this context is not always clear; notions of partnership are bound up with any number of overlapping ideas around 'engagement', so that we can talk about students as active partners, change agents, producers, or co-creators of their own learning. It is also clear that partnership takes place at different levels and scales, and in a range of contexts, from institution or department wide strategies and initiatives, to more local course, module, or assessment initiatives (Bovill et al. 2016; Healey Flint, and Harrington 2014).

Potential advantages of partnership include improving students' understanding of teaching and learning (Garcia, Noguera, and Cortada-Pujol 2018; Jensen and Bennett 2016; Marquis et al. 2016), improving students' confidence, communication skills and sense of belonging (Marquis et al. 2016; Moore-Cherry et al. 2016), and the enhancement of teaching and learning initiatives via greater understanding of the student perspective (Healey et al. 2013; Mihans, Long, and Felten 2008).

Currently, the role of student partnership in supporting the development, implementation, or evaluation of lecture capture systems appears to be underreported in the literature. The two projects reported here were each funded as a Cardiff University Student Education Innovation Project (CUSEIP), which were designed to support staff-student partnership by providing a bursary to underwrite summer placement opportunities, whereby students work with staff within schools and other university departments. For the purposes of this article, the two projects have been given distinct labels; CUSEIP UNI and CUSEIP SCHOOL. Table 1 describes the timeframe and objectives of each project.

Table 1. Overview of the CUSEIP projects reported in this article.

\begin{tabular}{ll}
\hline Project name & Description \\
\hline CUSEIP UNI & $\begin{array}{l}\text { Project undertaken in Summer 2017, coordinated by the central University } \\
\text { support team for lecture capture, and in partnership with a second year stu- } \\
\text { dent from the School of Chemistry. The scope of this project was university }\end{array}$ \\
& wide and aimed to research and disseminate the different ways university \\
& students utilise lecture recordings as part of their private study. The project \\
& sought to produce a framework to encourage students' effective and efficient \\
& use of lecture recordings and offer new ways of thinking about studying \\
& using digital technologies. The outputs of the project included a series of stu- \\
& dent-facing materials, such as an online tutorial and instructional videos
\end{tabular}

CUSEIP Project undertaken in summer 2018 in a large School in the College of Arts,

SCHOOL Humanities and Social Sciences. The placement in this case was a second year student from the School of Social Sciences, who worked closely with the School eLearning Team. The aim of the project was to provide the school and its students with insights to inform policy and practice at a time of challenging discussions around the implementation and use of lecture capture. While very much focused on the experience of students within the school, the project was designed in the context of the wider literature and with reference to the previous CUSEIP UNI project. As a result of this project, a report was produced that fed into the school's strategic discussions, while other outputs included advice around student communication and the development of two student facing resources 


\section{Research design}

Both CUSEIP projects were shaped by a position of pragmatism (Wahyuni 2012) and used mixed methods approaches in an attempt to examine the research topics. Here the research questions were the most important determinant of the research philosophy, and the researchers adopted both positivist and interpretivist positions within the scope of the projects.

\section{Methods}

Both projects designed independent online surveys that were distributed to students. CUSEIP UNI received 195 responses to a university-wide survey of lecture capture experience, with responses from all faculties, while CUSEIP SCHOOL received 118 responses from a single school, 95\% of which were undergraduate students.

Each project also involved conducting interviews with voluntary participants. For CUSEIP SCHOOL, the placement student carried out 10 semi-structured telephone interviews with fellow students from the school in question. For the CUSEIP UNI placement, five semi-structured interviews were conducted, both face-to-face and using online video technologies, whereby only students who had previous experience with lecture recordings were selected. Participants in these interviews were all current undergraduate students from various disciplines (medical engineering; engineering; physics and astronomy; psychology; and chemistry).

CUSEIP UNI participants also completed a 'learning timeline' document that attempted to document the study practices of the learners (Figure 1). For this data-collection exercise, participants were supplied Microsoft Word documents with a graphical representation of a timeline containing two critical teaching and learning events; 'lecture' and 'assessment'. Participants were asked to self-report the activities they typically perform prior, during and after these two events, and were free to add

\section{LEARNING TIMELINE}

Department: Psychology

Undergraduate

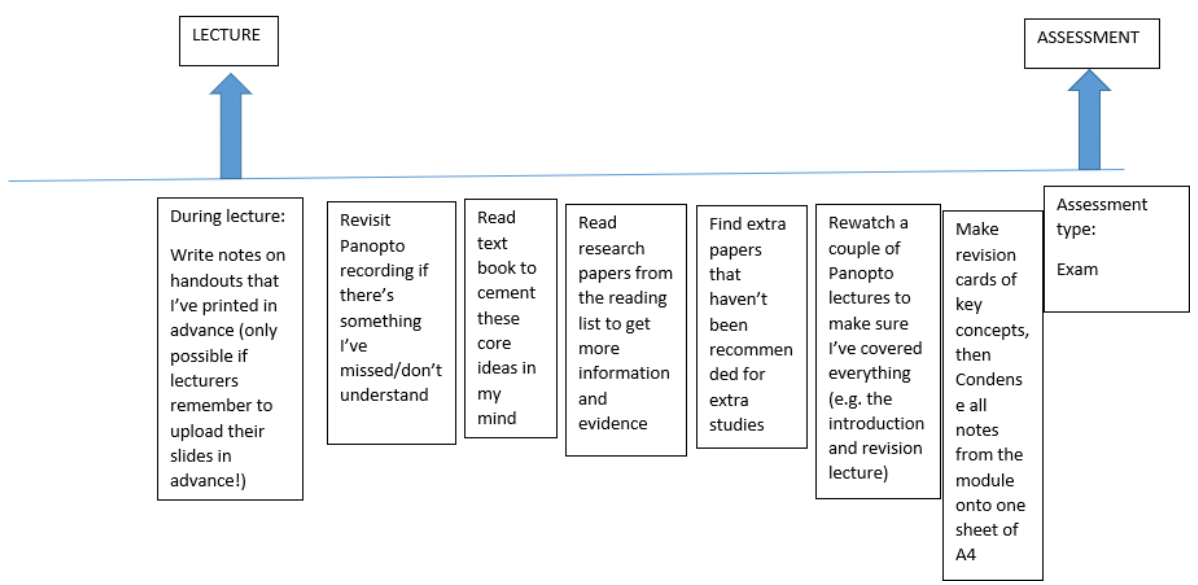

Figure 1. An example of a completed 'learning timeline' record. These self-reports documented study activities between the two learning events: 'lecture' and 'assessment'. 
as much content and detail to the report that they desired. The data collected was useful in understanding the range of activities undertaken by students as part of their learning and when these might occur.

Both projects also utilised data produced by the university's lecture-capture system. CUSEIP UNI analysed full system analytics to discover global trends and patterns in student usage across the whole institution, while CUSEIP SCHOOL looked at the faculty's usage statistics from the 2017/18 academic year, cross-referenced with data related to enrolment numbers, year groupings, and recording policy for each module.

\section{Partnership and co-creation}

Co-creation was an approach that underpinned the CUSEIP projects. Bovill et al. (2016) claimed that all partnerships involve co-creation and identified four roles that students may assume in the process of co-creation:

1. Consultant: students share and discuss perspectives on learning and teaching;

2. Co-researcher: students collaborate meaningfully on educational research or subject-based research;

3. Pedagogical co-designer: students share responsibility for designing learning, teaching, and assessment;

4. Representative: student voices contribute to decisions in a range of university settings.

Using these definitions there were naturally elements of the consultant role in the way in which the placement students interacted with staff, while through the surveys and interviews a network of students contributed their voices to decision making around lecture capture (and associated support) at various levels, thereby fulfilling a representative role.

Most importantly, however, it could be said that the students in both projects acted as co-researchers during the placements, with responsibility for shaping the research methodology and design undertaken. It was also hoped that interviewees would be candid when talking to a fellow student, and this was perceived as a strength of this approach. Moreover, the partnerships permitted access to specific student insights and perspectives, which actively shaped the development of specific questions not previously considered by faculty staff.

\section{Findings}

Triangulating data collected across both projects revealed insights into students' experiences, perceptions, and attitudes regarding lecture capture. The data also investigated study practices and explored how and when learners use recordings in an attempt to provide insight into why they use it and what they value about it.

Our analysis of the data supports many findings reported in current lecture capture literature, echoing the emerging consensus about the value students attach to lecture recordings and the ways in which they use them to support their learning (Nordmann and McGeorge 2018). It is clear from our findings that students highly value lecture recordings, while both the quantitative and qualitative data collected 
suggest students largely use recordings as a supplement to live lectures for revision purposes, to aid note-taking, to support homework tasks, and in the preparation for future teaching events. As an illustrative example, Figure 2 shows a large increase in recording views during exam periods, which is consistent with other studies (Witthaus and Robinson 2015). A distinct, yet related, insight is that the data reveals that students predominately use recordings selectively, to clarify or reinforce learning from lectures, usually through selective viewing of small sections (Karnad 2013; Witthaus and Robinson 2015).

The projects also garnered insights that advance perspectives, specifically the way some students use lecture recordings collaboratively. Self-reported data collected as part of the CUSEIP UNI project suggests that a significant portion of students $(25 \%$, $n=195$ ) watch recordings with others, such as in pairs or study groups, and actively engage in collaborative activities whilst watching recordings.

Such collaborative activities include discussion, group testing/quizzing, and collaborative note-taking (Figure 3). They seek to consolidate understanding and support revision, as evidenced by the free-text statements given in Table 2. It is also noteworthy that the practice of peer-working was reported by students across various disciplines, such as engineering, physics, business studies, social sciences, biosciences, and psychology. As such, collaborative study practices involving recordings do not appear to be isolated to particular domains, and span multiple areas, each with their own set of teaching practices, methods, and approaches.

Similarly, in the CUSEIP SCHOOL project almost a fifth of the 118 students surveyed claimed they watch recordings with other students either sometimes $(13.6 \%)$ or often $(4.9 \%)$. These findings were reflected in the survey; out of 10 students, two reported watching recordings with peers occasionally and one reported only watching with fellow students. Further questioning revealed that this student would discuss lecture content with friends, particularly when unsure about difficult concepts, and

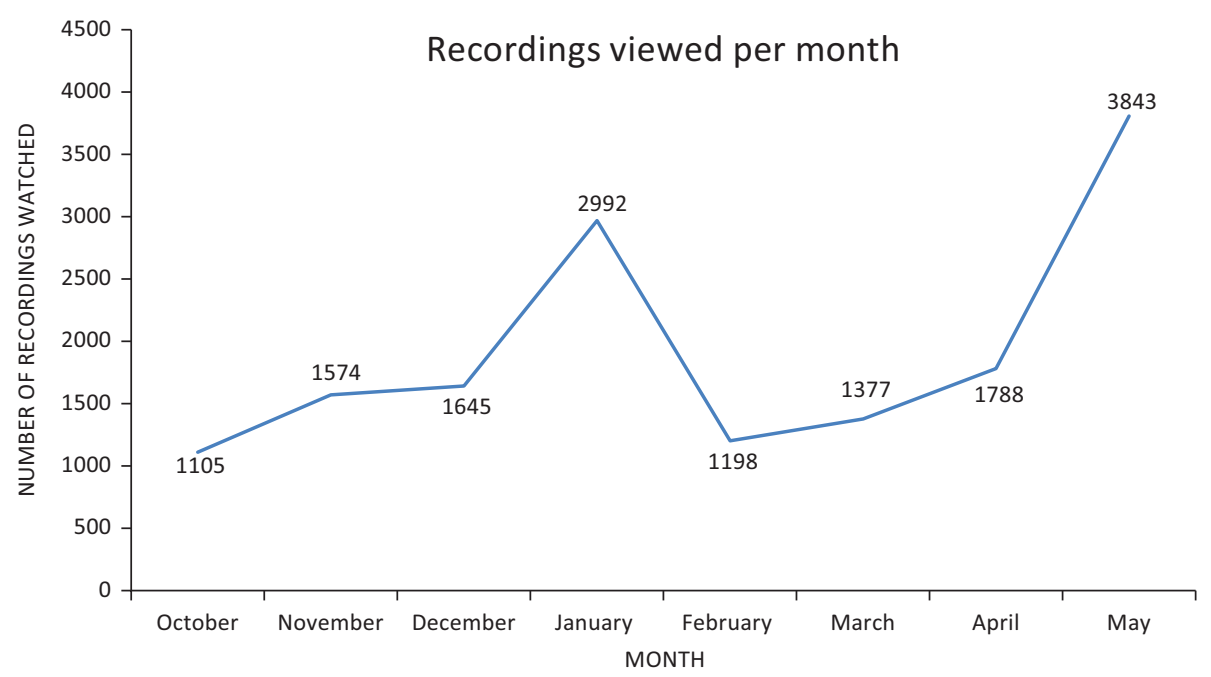

Figure 2. CUSEIP SCHOOL user data: there is a large increase in usage during the months of January and May, which are both exam periods. 


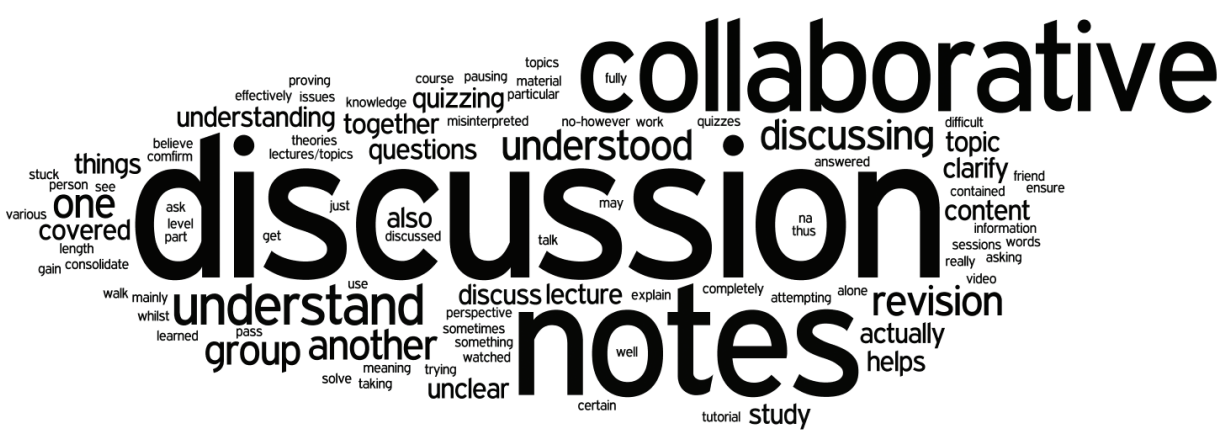

Figure 3. Word cloud made from the responses to the survey question: 'why do you watch lecture recordings with a group/pair and what kind of collaborative activities do you engage in?' $(N=195)$. The size of each word indicates the frequency in which it is mentioned in the responses.

Table 2. Free-text statements made in response to the online survey question 'why do you watch lecture recordings with a group/pair and what kind of collaborative activities do you engage in?'

\begin{tabular}{ll}
\hline Response & Discipline \\
\hline 'Collaborative notes and discussion, also trying to explain with our own & $\begin{array}{l}\text { UG mechanical } \\
\text { engineering }\end{array}$ \\
words what we just learned to see if we can actually pass that information to \\
another person effectively, thus proving that we have understood it as well' \\
'To consolidate knowledge, we discussed to ensure we all understood & $\begin{array}{l}\text { UG physics } \\
\text { student }\end{array}$ \\
various topics completely' & UG physics \\
'Both my friend and I were stuck in our understanding and watched it \\
through together whilst discussing the topic by pausing the video' & student \\
'Mainly discussion, sometimes collaborative notes and asking one & UG psychology \\
another questions' & student \\
'Discussion of more difficult material contained in lectures/topics which & UG biosciences \\
may have been unclear or not understood as fully' & student \\
\hline
\end{tabular}

often they would watch the recording together to revisit the content and arrive at a shared understanding.

\section{Discussion}

These projects have shown that a significant number of students use lecture recordings alongside other students, either in pairs or groups. It also appears that the emphasis is often on the same kinds of use widely reported in the literature; clarifying lecture content, assisting note-taking, and generally revising/reinforcing learning.

There are a number of limitations to this study: it includes only students from one HEI; there may be some sample bias in surveys and interviews (e.g. students who are interested in lecture capture being more likely to volunteer); much of the data is self-reported; and time limitations meant that some of the quantitative findings from the system data were not fully explored or triangulated with the qualitative methods 
(survey and interview). Most pertinently, as the central finding of the study (collaborative viewing of lecture recordings) was unanticipated, there was less emphasis on this aspect than would otherwise have been the case during the design of the surveys and interviews.

This being the case, the findings nonetheless position the reviewing of lecture recordings away from solely an individual study practice, which is how much of the research on this subject is currently considered. This raises a number of questions for institutions and practitioners, for example about the reliance on learning analytics to give us insights into student behaviour. There are also ethical questions around recording release policy and equity. How far are institutional or faculty policies that prioritise students with a special education need (and a support agreement) viable in an environment where some students watch recordings with their friends (who may not have a support agreement)?

Chi, Roy, and Hause (2008) have reported on the effectiveness of collaborative viewing of tutoring videos, and argue that such activity encourages learners to become active and constructive observers through interactions with peers. Such findings raise interesting possibilities relating to lecture capture and how peer working may be an effective learning strategy. There are fundamental questions about how watching recordings together, and engaging in discussion and other activities, changes the nature of learning (Nordmann et al. 2018).

These insights are enlightening, but how far they are actionable (and lead to changes in policy or practice) must necessarily be limited pending further understanding of the nuances contained within. For example, previous studies have reported that physical lecture attendance can be a useful predictor for attainment (Credé, Roch, and Kieszczynka 2010). With supplemental use of lecture recording largely conceptualised as being of individual use, more investigation is needed into whether reviewing lecture recordings as part of a peer-group negates any negative effects of non-attendance. Such research has potential implications for future policies and practice (Nordmann et al. 2018).

When attempting to examine the study practices involving lecture recordings, greater appreciation for the 'messy realties' (Law 2004) is required. Recent literature has explored the data provided by lecture capture solutions (Colthorpe et al. 2015; Phillips et al. 2012; Sarsfield and Conway 2018), yet collaborative and social viewing of lecture recordings has implications for how learning analytics are conceived and how data is interpreted. Learning analytics has been celebrated as enabling universities 'to track individual student engagement, attainment and progression' (Sclater and Mullan 2017, p. 6). Here, analytics typically record an individual's engagement with a digital artefact (i.e. one person interacting with a lecture recording), which in some cases may not be a true measure of engagement (i.e. where viewing takes place in groups/pairs). Scholars should therefore exercise caution when exploring the allure of learning analytics and continue to seek authentic understandings of how learners are mobilising lecture recordings in their studies. Triangulation of many sources (i.e. self-reported data, ethnographical studies, and learning analytics) should be sought, where possible, in an attempt to gain a clear picture of the realities present (Gorissen, Van Bruggen, and Jochems 2012).

Furthermore, a number of recent studies (French and Kennedy 2017; Mackay 2018; Meehan and McCallig 2019; Nordmann et al. 2018) argue that improved practical guidance for students (and staff) on how lecture recordings can be integrated effectively into learning practices is required. In an example of how this issue can be addressed, the CUSEIP SCHOOL project led to insights that directly impacted 
on the support provided to students, whereby staff created resources that: addressed the self-reported gap in students' knowledge of learning strategies to integrate lecture recordings effectively; and addressed students' confusion regarding local lecture capture policy within the school. More pertinently, the student on the CUSEIP UNI project designed and authored a number of online resources themselves, including posters, video tutorials, and an interactive online tutorial intended to support students' effective and efficient use of lecture recordings. These resources, illustrated in Figure 4, have been published on the university's student support website and the materials have been satisfactorily evaluated by students with feedback suggesting that learners rate their authenticity, relatability, and coherence. As such, it can also be argued that the placement students also undertook a pedagogical co-designer role (Bovill et al. 2016), whereby they were responsible for co-designing learning and teaching materials and resources.

Student partnership may afford educationalists a unique opportunity to engage in participatory conversations that bridge the gap between data (particularly in the form of learning analytics) and the real and varied learning experiences of individuals and groups of students. We have seen examples of partnership at school and university level, but there may be additional value in exploring lecture capture through partnership at the course level, encouraging academic staff to open detailed and creative conversations with their students about the use of lecture recordings in the learning process, in an attempt to design inclusive curricula and pedagogical approaches that best meet learners' needs (Morris, Swinnerton, and Coop 2019). Gaining more nuanced insight into study habits would no doubt assist with this.

Using Learn Plus

\section{Using the Panopto Viewer}

Viewing Panopto (Learn Plus) recordings online is really easy.

In the video below Cardiff student Ameen gives a quick overview of LearnPlus and how to use it. We then explore the main features in the following pages.

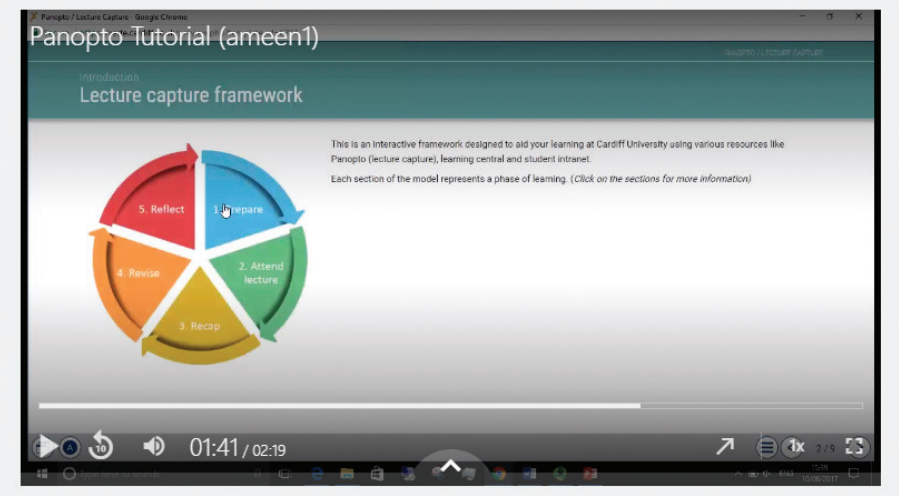

\section{Acessibility}

Figure 4. Screenshot showing a learning object created as a result of findings from the CUSEIP SCHOOL project. The page shown incorporates a video tutorial created by the student on the earlier CUSEIP UNI project. 


\section{Conclusion}

It is almost impossible to summarise concisely how, when, and why students use lecture recordings. Experience of the technology is impacted by a host of factors including availability, course content, institution policy, personal preference, and individual (and 'additional') learning needs. Often we are left with generalisations that may apply to a greater or lesser degree in any one case: students place high value on lecture recordings; students make more use of short clips than full recordings; and they regularly use lecture recordings for revision purposes. However, projects such as these can help to build a clearer picture of lecture capture use in different contexts and aid our understandings within the complex area of student experience. The partnership projects have exposed underreported areas, in particular student use of lecture recordings in collaborative settings, and their use of active learning strategies (Prince 2004).

As an emerging tool for students and staff alike, there are concerns that students may not have developed the necessary skills to effectively utilise lecture recordings (French and Kennedy 2017; Mackay 2018). Nordmann et al. (2018) call for a shift away from arguments regarding the limitations and merits of lecture capture to 'a more nuanced discussion about how best to use the technology in a way that is pedagogically effective for students and fair for academic staff' (ibid, p. 21). Criticality debating positions is of course part and parcel of academia, but educators should also recognise the complexity of teaching and learning within our digital age (Morris, Swinnerton, and Coop 2019; Luke 2020). This article has attempted to advance efforts in this area by highlighting the significant activity of viewing lecture recordings within a peer-group, something largely unreported previously. This article serves to provide a foundation for further research into the way students actually use lecture recordings, as opposed to assumptions regarding how they are used. Deeper investigations in this area could provide valuable insights in developing effective practices which support collaborative viewing, as well as technological enhancements to facilitate greater learning in such situations. Additionally, this article exposes how a simplistic reading of usage statistics, as part of a learning analytics approach, can misrepresent student activity significantly.

It has been argued that such insights were made possible by working in partnership with learners and exploring practices which may be 'hidden' from faculty view. The opportunities for educational technologies, such as lecture capture, to positively support learners should not be understated; working in partnership with learners to explore affordances and practices may lead to positive curricula change, with renewed opportunities to enhance teaching and learning.

\section{Acknowledgments}

The authors would like to express their gratitude to the two undergraduate students who undertook the CUSEIP projects - Ameen and Amy Davies - for their hard work and dedication during the placements. The authors would also like to extend their gratitude to the reviewers for their helpful and constructive feedback during the publication process.

\section{References}

Bovill, C., et al., 2016 'Addressing potential challenges in co-creating learning and teaching: overcoming resistance, navigating institutional norms and ensuring inclusivity in student-staff partnerships', Higher Education, vol. 71, no. 2, pp. 195-208. doi: 10.1007/ s10734-015-9896-4 
Cardiff University. (2018) The Way Forward 2018-2023: Education and Students SubStrategy, [online] Available at: https://www.cardiff.ac.uk/thewayforward/sub-strategies/ education-and-students

Chi, M. T., Roy, M. \& Hausmann, R. G. (2008) 'Observing tutorial dialogues collaboratively: insights about human tutoring effectiveness from vicarious learning', Cognitive Science, vol. 32, no. 2, pp. 301-341. doi: 10.1080/03640210701863396

Colthorpe, K., et al., (2015) 'Know thy student! Combining learning analytics and critical reflections to develop a targeted intervention for promoting self-regulated learning, Journal of Learning Analytics, vol. 2, no. 1, pp. 134-155. doi: 10.18608/jla.2015.21.7

Credé, M., Roch, S. G. \& Kieszczynka, U. M. (2010) 'Class attendance in college: a meta-analytic review of the relationship of class attendance with grades and student characteristics', Review of Educational Research, vol. 80, no. 2, pp. 272-295. doi: 10.3102/0034654310362998

Edwards, M. \& Clinton, M. (2019) 'A study exploring the impact of lecture capture availability and lecture capture usage on student attendance and attainment', Higher Education, vol. 77, no. 3, pp. 403-421. doi: 10.1007/s10734-018-0275-9

French, S. \& Kennedy, G. (2017) 'Reassessing the value of university lectures', Teaching in Higher Education, vol. 22, no. 6, pp. 639-654. doi: 10.1080/13562517.2016.1273213

Garcia, I., Noguera, I. \& Cortada-Pujol, M. (2018) 'Students perspective on participation in a co-design process of learning scenarios', The Journal of Educational Innovation, Partnership and Change, vol. 4, no. 1. doi: 10.21100/jeipc.v4i1.760

Gorissen, P., Van Bruggen, J. \& Jochems, W. (2012) 'Usage reporting on recorded lectures using educational data mining', International Journal of Learning Technology, vol. 7, no. 1, pp. 23-40. doi: 10.1504/IJLT.2012.046864

Healey, M., et al., (2013) 'Collaborative discipline-based curriculum change: applying change academy processes at department level', International Journal for Academic Development, vol. 18, no. 1, pp. 31-44. doi: 10.1080/1360144X.2011.628394

Healey, M., Flint, A. \& Harrington, K. (2014) Engagement Through Partnership: Students as Partners in Learning and Teaching in Higher Education, [online] Available at: https://www. heacademy.ac.uk/system/files/resources/engagement_through_partnership.pdf

Jensen, K. \& Bennett, L. (2016) 'Enhancing teaching and learning through dialogue: a student and staff partnership model', International Journal for Academic Development, vol. 21, no. 1, pp. 41-53. doi: 10.1080/1360144X.2015.1113537

Karnad, A. (2013) Student Use of Recorded Lectures: A Report Reviewing Recent Research into the Use of Lecture Capture Technology in Higher Education, and Its Impact on Teaching Methods and Attendance, [online] Available at: http://eprints.lse.ac.uk/50929/1/Karnad_ Student_use_recorded_2013_author.pdf

Law, J. (2004) After Method: Mess in Social Science Research, Routledge, London.

Leadbeater, W., et al., (2013) 'Evaluating the use and impact of lecture recording in undergraduates: evidence for distinct approaches by different groups of students', Computers and Education, vol. 61, pp. 185-192. doi: 10.1016/j.compedu.2012.09.011

Luke, K. (2020) 'The pause/play button actor-network: lecture capture recordings and (re) configuring multi-spatial learning practices', Interactive Learning Environments, doi: 10.1080/10494820.2019.1706052

Mackay, J. (2018) The Value of Lecture Recording at the University of Edinburgh, [online] Available at: https://www.teaching-matters-blog.ed.ac.uk/what-is-the-value-of-lecturerecording-at-the-university-of-edinburgh/

Marquis, E., et al., (2016) 'Navigating the threshold of student-staff partnerships: a case study from an Ontario teaching and learning institute', International Journal for Academic Development, vol. 21, no. 1, pp. 4-15. doi: 10.1080/1360144X.2015.1113538

McKenna, B. \& Kopittke, P. (2018) 'Engagement and performance in a first year natural resource science course', Journal of Computer Assisted Learning, vol. 34, no. 3, pp. 233-242. doi: $10.1111 /$ jcal.12236 
Meehan, M. \& McCallig, J. (2019) 'Effects on learning of time spent by university students attending lectures and/or watching online videos', Journal of Computer Assisted Learning, vol. 35, no. 2, pp. 283-293. doi: 10.1111/jcal.12329

Mihans, R., Long, D. \& Felten, P. (2008) 'Power and expertise: student-faculty collaboration in course design and the scholarship of teaching and learning', International Journal for the Scholarship of Teaching and Learning, vol. 2, no. 2, pp. 1-9. doi: 10.20429/ijsot1.2008.020216

Moore-Cherry, N., et al., (2016) 'Inclusive partnership: enhancing student engagement in Geography', Journal of Geography in Higher Education, vol. 40, no. 1, pp. 84-103. doi: 10.1080/03098265.2015.1066316

Morris, N., Swinnerton, B. \& Coop, T. (2019) 'Lecture recordings to support learning: a contested space between students and teachers', Computers \& Education, vol. 140, pp. 104-113. doi: 10.1016/j.compedu.2019.103604

Newland, B. (2017) Lecture Capture in UK HE: A HeLF Survey Report, [online] Available at: https:// research.brighton.ac.uk/en/publications/lecture-capture-in-uk-he-2017-a-helf-survey-report

Nordmann, E., et al., (2017) 'Turn up, tune in, don't drop out: the relationship between lecture attendance, use of lecture recordings, and achievement at different levels of study', Higher Education, vol. 77, no. 6, pp. 1065-1084. doi: 10.1007/s10734-018-0320-8

Nordmann, E., et al., (2018) 'Lecture capture: practical recommendations for students and lecturers', PsyArXiv. doi: 10.31234/osf.io/sd7u4

Nordmann, E. \& McGeorge, P. (2018) 'Lecture capture in higher education: time to learn from the learners', PsyArXiv. doi: 10.31234/osf.io/ux29v

O'Callaghan, F., et al., (2017) 'The use of lecture recordings in higher education: a review of institutional, student, and lecturer issues', Education and Information Technologies, vol. 22, no. 1, pp. 399-415. doi: 10.1007/s10639-015-9451-z

Phillips, R., et al., (2012) 'Exploring learning analytics as indicators of study behaviour', World Conference on Educational Multimedia, Denver, CO, pp. 2861-2867.

Prince, M. (2004) 'Does active learning work? A review of the research', Journal of Engineering Education, vol. 93, no. 3, pp. 223-231. doi: 10.1002/j.2168-9830.2004.tb00809.x

Rios-Amaya, J., Secker, J. \& Morrison, C. (2016) Lecture Recording in Higher Education: Risky Business Or Evolving Open Practice, LSE / University of Kent, [online] Available at: http:// eprints.lse.ac.uk/id/eprint/68275

Sarsfield, M. \& Conway, J. (2018) 'What can we learn from learning analytics? A case study based on an analysis of student use of video recordings', Research in Learning Technology, vol. 26. doi: 10.25304/rlt.v26.2087

Sclater, N. \& Mullan, J. (2017) Learning Analytics and Student Success: Assessing the Evidence, JISC, [online] Available at: http://repository.jisc.ac.uk/6560/1/learning-analytics_and_student_success.pdf

Traphagan, T., Kucsera, J. \& Kishi, K. (2010) 'Impact of class lecture webcasting on attendance and learning', Educational Technology Research and Development, vol. 58, no. 1, pp. 19-37. doi: 10.1007/s11423-009-9128-7

Wahyuni, D. (2012) 'The research design maze: understanding paradigms, cases, methods, and methodologies', Journal of Applied Management Accounting Research, vol. 10, no. 1, pp. 69-80.

Walker, R., et al., (2018) Survey of Technology Enhanced Learning for Higher Education in the UK, [online] Available at: https://www.ucisa.ac.uk/publications/tel_2018

Williams, M., et al., (2017) Models of Support for Students with Disabilities, Institute for Employment Studies, [online] Available at: https://www.employment-studies.co.uk/ resource/models-support-students-disabilities

Witthaus, G. \& Robinson, C. (2015) Lecture Capture Literature Review: A Review of the Literature from 2012 to 2015, Centre for Academic Practice, Loughborough, [online] Available at: https://dspace.lboro.ac.uk/dspace-jspui/bitstream/2134/25712/3/Witthaus_Lecture 